\title{
Beneficial effect of insulin-like growth factor-1 on hypoxemic renal dysfunction in the newborn rabbit
}

\author{
Anne Prévot • Monique Julita • David K. Tung • \\ Dolores Mosig
}

Received: 8 July 2008 /Revised: 2 December 2008 / Accepted: 2 December 2008 / Published online: 24 January 2009

(C) IPNA 2009

\begin{abstract}
Acute normocapnic hypoxemia can cause functional renal insufficiency by increasing renal vascular resistance (RVR), leading to renal hypoperfusion and decreased glomerular filtration rate (GFR). Insulin-like growth factor 1 (IGF-1) activity is low in fetuses and newborns and further decreases during hypoxia. IGF-1 administration to humans and adult animals induces preand postglomerular vasodilation, thereby increasing GFR and renal blood flow (RBF). A potential protective effect of IGF-1 on renal function was evaluated in newborn rabbits with hypoxemia-induced renal insufficiency. Renal function and hemodynamic parameters were assessed in 17 anesthetized and mechanically ventilated newborn rabbits. After hypoxemia stabilization, saline solution (time control) or
\end{abstract}

Presented orally at the yearly meeting of the French Society of Pediatric Nephrology (SNP), Amsterdam, The Netherlands, 17-19 November 2005.

Presented as an oral/poster at the 40th Annual Meeting of the European Society for Pediatric Nephrology (ESPN), Palermo, Italy, 710 October 2006.

A. Prévot $\cdot$ M. Julita $\cdot$ D. Mosig

Nephrology Unit, Department of Pediatrics,

Lausanne University Medical Center (CHUV),

Lausanne, Switzerland

D. K. Tung

Department of Medicine/Physiology, University of Fribourg,

Chemin du Musée 5,

1700 Fribourg, Switzerland

Present address:

A. Prévot $(\square)$

Department of Medicine/Physiology, University of Fribourg,

Chemin du Musée 5,

1700 Fribourg, Switzerland

e-mail: prevotanne@hotmail.com
IGF-1 (1 mg/kg) was given as an intravenous (i.v.) bolus, and renal function was determined for six 30 -min periods. Normocapnic hypoxemia significantly increased RVR $(+16 \%)$, leading to decreased GFR $(-14 \%)$, RBF $(-19 \%)$ and diuresis $(-12 \%)$, with an increased filtration fraction (FF). Saline solution resulted in a worsening of parameters affected by hypoxemia. Contrarily, although mean blood pressure decreased slightly but significantly, IGF-1 prevented a further increase in RVR, with subsequent improvement of GFR, RBF and diuresis. FF indicated relative postglomerular vasodilation. Although hypoxemiainduced acute renal failure was not completely prevented, IGF-1 elicited efferent vasodilation, thereby precluding a further decline in renal function.

Keywords Hypoxemia - Insulin-like growth factor-1 . Kidney $\cdot$ Newborn rabbit $\cdot$ Survival

\section{Introduction}

Perinatal asphyxia is a leading cause of neonatal morbidity and mortality. Acute renal failure (ARF) related to perinatal asphyxia accounts for the majority of ARF cases in newborns, along with hypovolemia and hypotension [1, 2]. In clinical observations and preclinical animal models, acute normocapnic hypoxemia can induce functional renal insufficiency by increasing the renal vascular resistance (RVR), thus leading to renal hypoperfusion and decreased glomerular filtration rate (GFR). The pathophysiologic mechanisms of this vasomotor nephropathy involve numerous local and humoral vasoactive agents. Previous studies from our laboratory have demonstrated that hypoxemia induces an alteration in the balance of local vasomediators in the newborn rabbit's kidney, including the vasoconstrictors adenosine and 
angiotensin II [3-5], as well as the vasodilator nitric oxide (NO) [6].

Insulin-like growth factor 1 (IGF-1) is a single-chain peptide growth factor with metabolic, mitogenic, anti-apoptotic and vasoactive properties [7, 8]. The growth hormone (GH)/ IGF-1 axis is the key endocrine and paracrine/autocrine regulator of both pre- and postnatal whole-body growth [912]. Plasma concentrations of IGF-1 and IGF-2 in the fetus positively correlate with birth weight in numerous species, including humans, primates, sheep, pigs, rodents and rabbits $[13,14]$.

In the adult kidney, in situ hybridization studies have shown that synthesis of IGF-1 occurs in various parts of the nephron [7], with IGF-1 receptors being present in glomeruli and on the basolateral membrane of renal proximal tubular cells [15-17]. Data from a rabbit model of intra-uterine growth retardation (IUGR) indicate that the rabbit fetal kidney expresses IGF-1 mRNA during late gestation and at birth [13]. In the developing rat kidney IGF-1 mRNA levels show a linear increase throughout the first month of postnatal life [1]. Likewise, in the developing rabbit tubular IGF-1 receptor, mRNA levels increase during terminal maturation of the tubules in the first three postnatal weeks [18].

Serum IGF-1 levels have been shown to be reduced in hypoxic-ischemic newborns $[19,20]$. In the fetal sheep, asphyxia induced by complete umbilical cord occlusion for 30 min leads to a decrease in circulating levels of IGF-1 [21]. In animal models of ARF, administration of IGF-1 accelerates the recovery of renal function, improves renal histology, and decreases the catabolic state [22, 23]. Acute IGF-1 administration to humans and adult animals induces both pre- and postglomerular vasodilation, thereby increasing renal blood flow (RBF) and GFR $[8,22,24]$.

We thus investigated the renal hemodynamic effects of the acute administration of IGF-1 in a newborn rabbit model of hypoxemia-induced ARF, which shows great similarities to those in the developing kidney of the human premature infant [25].

\section{Methods}

\section{Animal experiments}

The animal studies were performed according to the guidelines of the Swiss National Science Foundation.

A total of 17 newborn, New Zealand White rabbits, $6.5 \pm$ 0.3 days old [mean \pm standard error of the mean (SEM), range 5-9 days] survived the experiment and their data were used for the final statistical analysis. All animals, weighing $123.1 \pm 5.6 \mathrm{~g}$, had been born in our own animal facilities by spontaneous vaginal delivery and had been suckled normally until the time of study.
All the methods have been described previously $[3,5]$. Briefly, the rabbits were anesthetized by intraperitoneal injection of $25 \mathrm{mg} / \mathrm{kg}$ body weight (BW) of sodium pentobarbital and were artificially ventilated via tracheotomy with an oxygen-enriched gas mixture (respiratory rate 40 breaths/min, tidal volume adjusted for age and weight). Internal body temperature was maintained in the range of physiological values for rabbits (i.e. $39^{\circ} \mathrm{C}$ ). Catheters were implanted into the femoral vessels for venous solute infusion, arterial blood sampling, and continuous monitoring of mean arterial blood pressure (MAP) and heart rate (HR). Urine was sampled by bladder catheterization.

After completion of the surgical procedure, inulin and para-aminohippuric acid (PAH) clearances were measured throughout the experiment. From this point onward, all animals were given a constant infusion of a modified rabbit Ringer solution at a rate of $1 \mathrm{ml} / \mathrm{h}$ per $100 \mathrm{~g} \mathrm{BW}[3,5]$.

\section{Experiment protocol}

The experimental protocol (Fig. 1) was started on all animals after a $90-\mathrm{min}$ equilibration period by a $60-\mathrm{min}$ normoxemic control period (C), consisting of two 30-min collections of urine, and $0.4 \mathrm{ml}$ of blood withdrawn at the midpoint of each collection. Eighty microliters were used for immediate measurement of blood gases, glucose, hematocrit and plasma protein levels. The red blood cells were reconstituted in diluted human albumin and reinfused. The remainder of the plasma was kept at $-20^{\circ} \mathrm{C}$ for later determination of electrolytes and renal function markers. Results are given as means of the two urine collections.

We then induced acute hypoxemia (period Hx) over $30 \mathrm{~min}$ by reducing the fractional inspiratory oxygen concentration with a gas mixture of $1 \%$ oxygen $\left(\mathrm{O}_{2}\right)$ and $90 \%$ nitrogen $\left(\mathrm{N}_{2}\right)$, in order to reach a partial pressure of arterial oxygen $\left(\mathrm{PaO}_{2}\right)$ of approximately $40-50 \mathrm{mmHg}[3$, 5]. Hypoxemia was maintained at the same $\mathrm{PaO}_{2}$ level until the end of the experiment.

The animals were then randomly divided in two age- and weight-matched groups. All animals were given an intravenous (i.v.) bolus of $500 \mu \mathrm{l} / 100 \mathrm{~g}$ of their respective treatment within $2 \mathrm{~min}$, flushed with heparinized saline solution for an additional $3 \mathrm{~min}$. The treatment groups were:

- Group $\mathrm{NaCl}$ : isotonic saline solution, $n=8$, age $6.4 \pm 0.5$ days, weight $127.9 \pm 8.7 \mathrm{~g}$.

- Group IGF-1: $1 \mathrm{mg} / \mathrm{kg}$ IGF-1 (Chiron Corporation, Emeryville, CA, USA), $n=9$, age $6.6 \pm 0.5$ days, weight $118.8 \pm 7.5 \mathrm{~g}$.

The dose of IGF-1 and way of administration were optimized in a preliminary study performed on normoxemic 
Fig. 1 Experimental protocol in the two groups $\left(\mathrm{PaO}_{2}\right.$ partial pressure of arterial oxygen, i.v. intravenous)

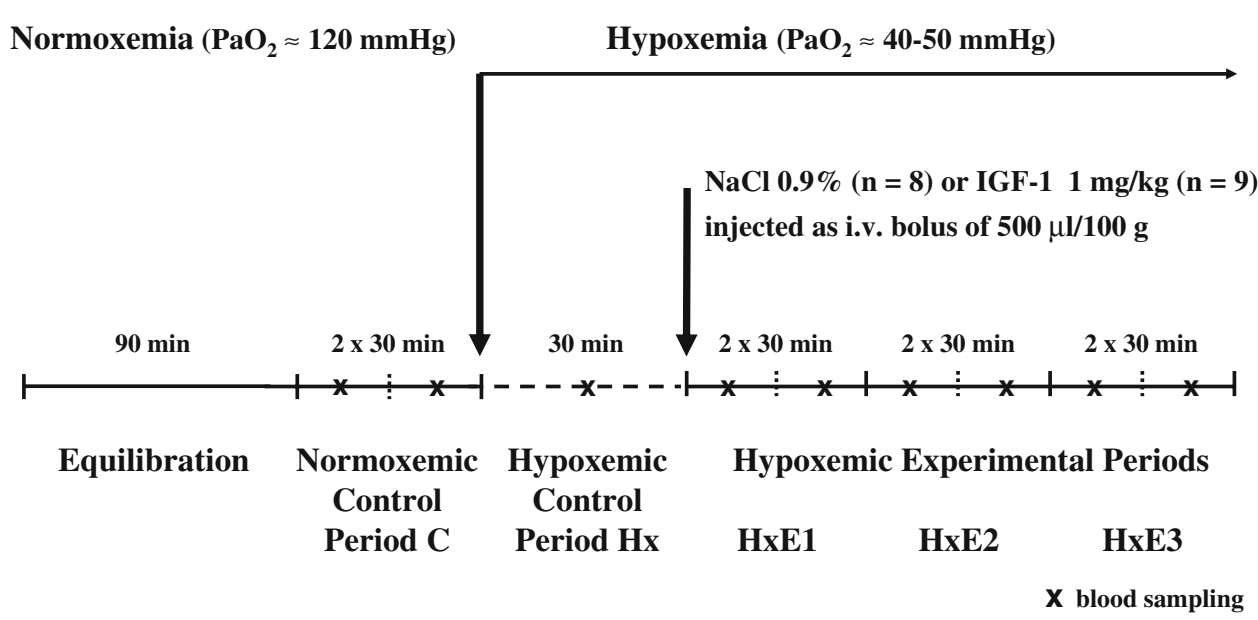

newborn rabbits. IGF-1 at $1 \mathrm{mg} / \mathrm{kg}$ was effective on renal function throughout the time-course of the present study, without significantly affecting MAP [26].

Renal function was measured for three additional periods (HxE1, HxE2, HxE3), each comprising two 30-min urine collections, and $0.4 \mathrm{ml}$ of blood was withdrawn at the midpoint of each collection; the red blood cells were again reconstituted and re-infused. The results from each period are the means of the two urine collections.

\section{Analytical procedures}

Urine volume (UV) was assessed gravimetrically. Blood gas was measured with a $\mathrm{pH} /$ blood gas analyzer (Blood gas system 248, Bayer Schweiz AG, Zürich, Switzerland). The automatic anthrone method of Wright and Gann [27] and the method of Bratton and Marshall [28] were used for the determination of inulin and $\mathrm{PAH}$ concentrations, respectively (AutoAnalyzer II, Bran \& Luebbe, Nordestedt, Germany). Whole-blood glucose was assessed with a blood glucose monitoring system (Glucometer Elite ${ }^{\circledR}$ and Ascensia Elite $^{\circledR}$ blood glucose test strips, Bayer Schweiz AG, Zürich, Switzerland). Inulin and PAH clearances were calculated from standard equations representing GFR and renal plasma flow, respectively. Renal blood flow, filtration fraction (FF), and renal vascular resistance (RVR) were derived from standard equations as previously reported [5].

\section{Statistical analysis}

Only data from the animals that had undergone the whole experiment were included in the final results of the renal function parameters ( $n=8$ and $n=9$, respectively) (Fig. 2).

All results are presented as means \pm SEMs. $P<0.05$ was considered as statistically significant.

Inter-group difference of absolute values (Table 1) during the control and hypoxemia periods ( $\mathrm{C}$ and $\mathrm{Hx}$ ) was tested by the non-parametric Mann-Whitney test. As it was not significant for all parameters, this allowed us to pool the results. Comparison between control and $\mathrm{Hx}$ periods was then performed with the non-parametric Wilcoxon matched-pairs signed-ranks test.

Intra-group comparisons of absolute values (Tables 2 and 3 ) in the two treatment groups between the hypoxemic period $\mathrm{Hx}$ and experimental periods $\mathrm{HxE} 1, \mathrm{HxE} 2$ and HxE3 were performed with the non-parametric Friedman test [repeated measures analysis of variance (ANOVA)] followed by the Wilcoxon matched-pairs signed-ranks test. Each animal acted as its own control.

Survival rates were compared using chi-square analysis.

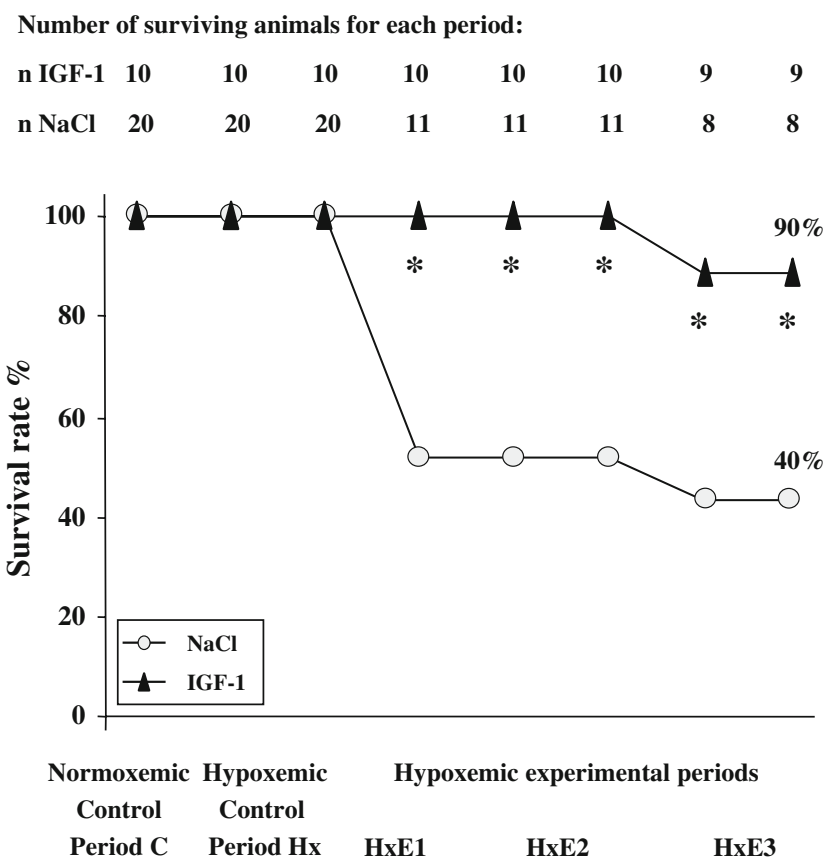

Fig. 2 Survival rates in percent. Survival was dependent on treatment with IGF-1 when compared with treatment with sodium chloride $(\mathrm{NaCl})$, when the chi-square test was utilized. Asterisks indicate $P<0.05$ 
Table 1 Absolute values of mean arterial pressure $(M A P)$, heart rate $(H R)$, hematocrit (Htc), plasma protein levels (Prot), blood gases systemic $\mathrm{pH}$, urine volume $(U V)$, glomerular filtration rate $(G F R)$, renal blood flow $(R B F)_{2}$ filtration fraction $(F F)$ and renal vascular

\begin{tabular}{llll}
\hline Parameter & $\begin{array}{l}\text { Normoxemic control period } \\
\mathrm{C}(n=17)\end{array}$ & $\begin{array}{l}\text { Hypoxemic control period } \\
\mathrm{Hx}(n=17)\end{array}$ & $P$ value Wilcoxon signed ranks test \\
\hline $\mathrm{MAP}(\mathrm{mmHg})$ & $32.5 \pm 0.8$ & $29.5 \pm 0.7$ & 0.0003 \\
$\mathrm{HR}($ per min) & $274 \pm 7$ & $271 \pm 8$ & $\mathrm{NS}$ \\
$\mathrm{Htc}(\%)$ & $32.8 \pm 0.7$ & $31.9 \pm 0.7$ & 0.0156 \\
$\mathrm{Prot}(\mathrm{g} / \mathrm{l})$ & $27.5 \pm 1.1$ & $26.1 \pm 0.9$ & 0.0005 \\
$\mathrm{PaO}(\mathrm{mmHg})$ & $132.8 \pm 3.0$ & $50.4 \pm 1.6$ & $<0.0001$ \\
$\mathrm{PaCO}(\mathrm{mmHg})$ & $43.9 \pm 0.5$ & $38.6 \pm 0.7$ & $<0.0001$ \\
$\mathrm{pH}$ & $7.43 \pm 0.01$ & $7.46 \pm 0.01$ & $<0.0001$ \\
$\mathrm{UV}(\mathrm{ml} / \mathrm{kg} \mathrm{per} \mathrm{min)}$ & $0.086 \pm 0.005$ & $0.073 \pm 0.005$ & 0.0232 \\
$\mathrm{GFR}(\mathrm{ml} / \mathrm{kg}$ per min) & $2.00 \pm 0.12$ & $1.72 \pm 0.13$ & 0.0056 \\
$\mathrm{RBF}(\mathrm{ml} / \mathrm{kg}$ per min) & $18.7 \pm 1.1$ & $15.2 \pm 1.1$ & 0.0008 \\
FF $(\%)$ & $16.0 \pm 0.4$ & $16.7 \pm 0.4$ & 0.011 \\
$\mathrm{RVR}(\mathrm{mmHg} / \mathrm{ml}$ per kg per min) & $1.82 \pm 0.09$ & $2.13 \pm 0.18$ & 0.0202 \\
\hline
\end{tabular}

resistance $(R V R)$ in newborn rabbits during normoxemic and hypoxemic control periods. Values are means \pm SEMs. Inter-group difference was tested by the non-parametric Kruskal-Wallis test and was shown to be not significant for all parameters, thus allowing us to pool the results. NS not significant

Hypoxemic control period $\quad P$ value Wilcoxon signed ranks test $\left[\mathrm{PaO}_{2}\right.$ and partial pressure of arterial carbon dioxide $\left.\left(\mathrm{PaCO}_{2}\right)\right]$,

\section{Results}

The two groups were similar in age, weight, all baseline control data and all data collected during the hypoxemia period. Therefore, we pooled data to present the overall effects of hypoxemia on renal function (Table 1).

During the experiments relatively minor, albeit statistically significant, changes in plasma protein levels and hematocrit were observed. These were artifacts in the neonatal animal experiments resulting from repeated blood sampling for $\mathrm{PaO}_{2}$ monitoring. We previously demonstrated that these changes do not interfere with the physiologic stability of the neonatal model [29].

Although changes were seen in $\mathrm{PaO}_{2}$, partial pressure of arterial carbon dioxide $\left(\mathrm{PaCO}_{2}\right)$ and $\mathrm{pH}$ levels over time, these changes remained minor and were not physiologically relevant (Table 2). The normocapnic hypoxemia can thus be considered as having been well maintained in the two groups throughout the experiment.

Hypoxemia significantly decreased MAP (-9\%), GFR $(-14 \%)$, RBF $(-19 \%)$, and diuresis $(-12 \%)$, while RVR and FF increased by $16 \%$ and $5 \%$, respectively (Table 1 ).

Sodium chloride $(\mathrm{NaCl})$ administration induced additional deterioration over time of all the parameters affected by hypoxemia (Tables 2 and 3). RVR further increased by 92\% (maximal increase at HxE3), while MAP (-17\%), GFR (-38\%), RBF (-45\%) and diuresis (-26\%) decreased. FF remained stable.

Although GFR, RBF and diuresis tended to decrease during HxE1 and HxE2, IGF-1 administration completely prevented a further rise in RVR, leading to a recovery of the parameters of renal function during $\mathrm{HxE} 3$. Indeed, GFR, $\mathrm{RBF}$ and diuresis increased from $\mathrm{HxE} 2$ to $\mathrm{HxE} 3$ and were not significantly reduced when compared with the hypoxemic control period $\mathrm{Hx}$ during $\mathrm{HxE}$. Meanwhile, FF showed a tendency to decrease, although not reaching significance $(P=0.09)$.

Supplementary results showed that IGF-1 seemed to have an overall protective effect against hypoxemia. Indeed, survival rates of the pups at the end of the experiment were $40 \%$ in the saline-treated group, compared with $90 \%$ in the IGF-1 group. In other words, in the $\mathrm{NaCl}$ group, 12 animals died before HxE3, whereas only one in the IGF-1 group died. Chi square analysis showed a statistically significant effect of IGF-1 treatment as early as the second 30-min period of urine collection (Fig. 2).

Whole-blood glucose levels remained stable with saline solution and were dramatically reduced as soon as IGF-1 administration was started, from $7.4 \pm 0.9 \mathrm{mmol} / 1$ to a nadir of $3.5 \pm 1.4 \mathrm{mmol} / \mathrm{l}$ (Fig. 3).

\section{Discussion}

As we previously reported, acute normocapnic hypoxemia in newborn rabbits was associated with a significant increase in RVR and a concomitant decline in RBF, GFR, MAP and diuresis [3-6, 25]. We formerly demonstrated that renal hypoperfusion has a vasomotor origin and that the underlying mechanisms involve the complex activation and interaction of vasoconstrictor and vasodilator factors acting on renal arterioles, including angiotensin II [5], adenosine [3, 4], or NO [6].

$\mathrm{NaCl}$ administration showed a further deterioration of MAP by $-17 \%$ during period HxE3 compared with the hypoxemic control period Hx. The RVR was significantly 
Table 2 Absolute values showing the effect of i.v. administration of sodium chloride $(\mathrm{NaCl})$ or IGF-1 $(1 \mathrm{mg} / \mathrm{kg})$ on mean arterial pressure $(M A P)$, heart rate $(H R)$, hematocrit $(H t c)$, plasma protein levels (Prot), blood gases $\left[\mathrm{PaO}_{2}\right.$ and partial pressure of arterial carbon dioxide $\left.\left(\mathrm{PaCO}_{2}\right)\right]$ and systemic $\mathrm{pH}$ in hypoxemic newborn rabbits. Values are means \pm SEMs. $H x$ hypoxemic control period, $H x E 1, H x E 2$ and $H x E 3$ hypoxemic experimental periods 1,2 and 3 (Fig. 1)

\begin{tabular}{|c|c|c|c|}
\hline Parameter & & $\mathrm{NaCl}(n=8)$ & IGF-1 $(n=9)$ \\
\hline \multirow[t]{4}{*}{ MAP (mmHg) } & $\mathrm{Hx}$ & $30.4 \pm 1.0 * * *$ & $28.8 \pm 0.8 * *$ \\
\hline & HxE1 & $27.6 \pm 0.9 \#$ & $26.7 \pm 0.7 \#$ \\
\hline & HxE2 & $26.2 \pm 1.1 \#$ & $24.6 \pm 0.8 \#$ \\
\hline & HxE3 & $25.1 \pm 1.6 \#$ & $26.1 \pm 0.8 \#$ \\
\hline \multirow[t]{4}{*}{ HR (per min) } & $\mathrm{Hx}$ & $286 \pm 11$ & $258 \pm 10 * * *$ \\
\hline & HxE1 & $281 \pm 11$ & $277 \pm 12 \# \#$ \\
\hline & HxE2 & $292 \pm 12$ & $285 \pm 12 \# \#$ \\
\hline & HxE3 & $287 \pm 11$ & $289 \pm 12 \#$ \\
\hline \multirow[t]{4}{*}{ Htc $(\%)$} & $\mathrm{Hx}$ & $31.0 \pm 1.1 * * *$ & $32.8 \pm 0.8^{* * *}$ \\
\hline & HxE1 & $29.4 \pm 1.1 \#$ & $29.6 \pm 0.6 \# \#$ \\
\hline & HxE2 & $28.3 \pm 1.1 \#$ & $27.7 \pm 0.6 \# \#$ \\
\hline & HxE3 & $26.6 \pm 0.9 \#$ & $27.1 \pm 0.8 \#$ \\
\hline \multirow[t]{4}{*}{ Prot (g/l) } & $\mathrm{Hx}$ & $25.0 \pm 1.6$ & $27.0 \pm 1.1 * * *$ \\
\hline & HxE1 & $24.6 \pm 1.4$ & $25.1 \pm 0.8 \# \#$ \\
\hline & HxE2 & $24.5 \pm 1.0$ & $23.9 \pm 0.6 \# \#$ \\
\hline & HxE3 & $25.1 \pm 0.9$ & $25.1 \pm 0.8 \#$ \\
\hline \multirow[t]{4}{*}{$\mathrm{PaO}_{2}(\mathrm{mmHg})$} & $\mathrm{Hx}$ & $52.2 \pm 2.0^{*}$ & $48.8 \pm 2.4$ \\
\hline & HxE1 & $43.2 \pm 1.4 \#$ & $42.3 \pm 1.1$ \\
\hline & HxE2 & $43.2 \pm 0.6 \#$ & $41.2 \pm 1.4 \#$ \\
\hline & HxE3 & $43.4 \pm 2.0 \#$ & $41.5 \pm 1.1 \#$ \\
\hline \multirow[t]{4}{*}{$\mathrm{PaCO}_{2}(\mathrm{mmHg})$} & $\mathrm{Hx}$ & $38.2 \pm 1.1$ & $39.0 \pm 1.0^{*}$ \\
\hline & HxE1 & $39.9 \pm 0.6$ & $40.0 \pm 1.8$ \\
\hline & HxE2 & $40.2 \pm 1.1$ & $43.4 \pm 1.4 \#$ \\
\hline & HxE3 & $38.9 \pm 1.3$ & $40.1 \pm 1.0$ \\
\hline \multirow[t]{4}{*}{$\mathrm{pH}$} & $\mathrm{Hx}$ & $7.47 \pm 0.01$ & $7.46 \pm 0.01 * *$ \\
\hline & HxE1 & $7.46 \pm 0.01$ & $7.45 \pm 0.01$ \\
\hline & HxE2 & $7.45 \pm 0.01$ & $7.41 \pm 0.01 \#$ \\
\hline & HxE3 & $7.44 \pm 0.01$ & $7.43 \pm 0.01 \#$ \\
\hline
\end{tabular}

${ }^{*} P$ value of the Friedman test [non-parametric repeated measures analysis of variance (ANOVA) for the three periods compared as a whole to the Hx control period $(* P<0.05 ; * * P<0.01 ; * * * P<0.001)]$ $\# P$ value of further analysis for each experimental period compared with the $\mathrm{Hx}$ control period with the non-parametric Wilcoxon matched-pairs signed-ranks test ( $\# P<0.05$; \#\#P<0.01)

increased by a maximum of $92 \%$, resulting in a significant time-dependent decrease in GFR, RBF and diuresis. We reported in the normoxemic newborn rabbit that infusion of saline solution had no significant effect on MAP and renal function over time, demonstrating the stability of the model [29]. Therefore, the further deterioration of hemodynamics and renal function observed here can be considered as a specific effect of hypoxemia. The stable FF indicated both pre- and postglomerular vasoconstriction, probably as the result of a combination of actions of hypoxemia on renal and peripheral microcirculations, as indicated by the increase in RVR and decrease of MAP. The renal response can thus be considered, at least partly, as a reflex vasoconstriction of both afferent and efferent arterioles to try and minimize changes in GFR, and hence maintain the regulation of intrarenal vascular tone. We previously demonstrated that the renin-angiotensin system (RAS) is critically involved in this phenomenon in the neonatal period in normoxemic as well as hypoxemic conditions [30,31].

In the preterm fetal sheep, asphyxia provoked by cord occlusion for 30 min was followed by a substantial fall in circulating plasma levels of IGF-1 detected $4 \mathrm{~h}$ after asphyxia [21]. Likewise, following $3 \mathrm{~h}$ of isocapnic hypoxia in the fetal sheep, the plasma levels of IGF-1 were reduced by approximately $35-40 \% 1 \mathrm{~h}$ after hypoxia [32]. In full-term human newborns with clinical signs of perinatal asphyxia, serum IGF-1 levels were significantly lower than in the control group 12-24 $\mathrm{h}$ after birth but also 10 days later [19]. Administration of exogenous IGF-1 might thus blunt any effect linked to this decrease. Indeed, in our model, i.v. infusion of exogenous IGF-1 totally prevented the hypoxemia-induced increase in RVR seen in the $\mathrm{NaCl}$ group, with a subsequent improvement of GFR, RBF and diuresis during HxE3 (Table 3). Meanwhile, MAP still

Table 3 Absolute values showing the effect of i.v. administration of sodium chloride $(\mathrm{NaCl})$ or IGF-1 $(1 \mathrm{mg} / \mathrm{kg})$ on urine volume $(\mathrm{UV})$, glomerular filtration rate $(G F R)$, renal blood flow $(R B F)$, filtration fraction $(F F)$ and renal vascular resistance $(R V R)$ in hypoxemic newborn rabbits. Values are means \pm SEMs. $H x$ hypoxemic control period, $H x E 1, H x E 2$ and $H x E 3$ hypoxemic experimental periods 1,2 and 3 (Fig. 1)

\begin{tabular}{llll}
\hline Parameter & & NaCl $(n=8)$ & IGF-1 $(n=9)$ \\
\hline UV (ml/kg per min) & Hx & $0.076 \pm 0.005$ & $0.071 \pm 0.009$ \\
& HxE1 & $0.069 \pm 0.006$ & $0.058 \pm 0.005$ \\
& HxE2 & $0.067 \pm 0.006$ & $0.051 \pm 0.005 \#$ \\
& HxE3 & $0.056 \pm 0.010 \#$ & $0.066 \pm 0.006$ \\
GFR (ml/kg per min) & Hx & $1.85 \pm 0.09^{* * *}$ & $1.61 \pm 0.23 * *$ \\
& HxE1 & $1.59 \pm 0.16 \#$ & $1.51 \pm 0.19$ \\
& HxE2 & $1.47 \pm 0.16 \#$ & $1.22 \pm 0.17 \#$ \\
& HxE3 & $1.15 \pm 0.22 \#$ & $1.30 \pm 0.19$ \\
RBF $(\mathrm{ml} / \mathrm{kg}$ per min) & Hx & $16.0 \pm 0.9 * * *$ & $14.5 \pm 2.0 *$ \\
& HxE1 & $13.3 \pm 1.4$ & $12.8 \pm 1.8$ \\
& HxE2 & $12.0 \pm 1.3 \#$ & $11.0 \pm 1.7 \#$ \\
& HxE3 & $8.9 \pm 1.5 \#$ & $11.6 \pm 1.9$ \\
FF $(\%)$ & Hx & $16.9 \pm 0.6$ & $16.5 \pm 0.6$ \\
& HxE1 & $17.0 \pm 0.5$ & $17.4 \pm 0.8$ \\
& HxE2 & $17.1 \pm 0.3$ & $15.7 \pm 0.8$ \\
& HxE3 & $16.7 \pm 1.0$ & $15.7 \pm 0.9$ \\
& Hx & $1.92 \pm 0.10^{* *}$ & $2.32 \pm 0.33$ \\
& HxE1 & $2.28 \pm 0.27$ & $2.45 \pm 0.33$ \\
RVR $(\mathrm{mmHg} / \mathrm{ml}$ per kg per min & HxE2 & $2.35 \pm 0.24 \#$ & $2.72 \pm 0.43$ \\
& HxE3 & $3.68 \pm 0.68 \#$ & $2.69 \pm 0.43$ \\
\hline
\end{tabular}

* $P$ value of the Friedman test (non-parametric repeated measures ANOVA) for the three periods compared as a whole to the Hx control period $(* P<0.05 ; * * P<0.01 ; * * * P<0.001)$

$\# P$ value of further analysis for each experimental period compared with the $\mathrm{Hx}$ control period with the non-parametric Wilcoxon matched-pairs signed-ranks test $(\# P<0.05)$ 


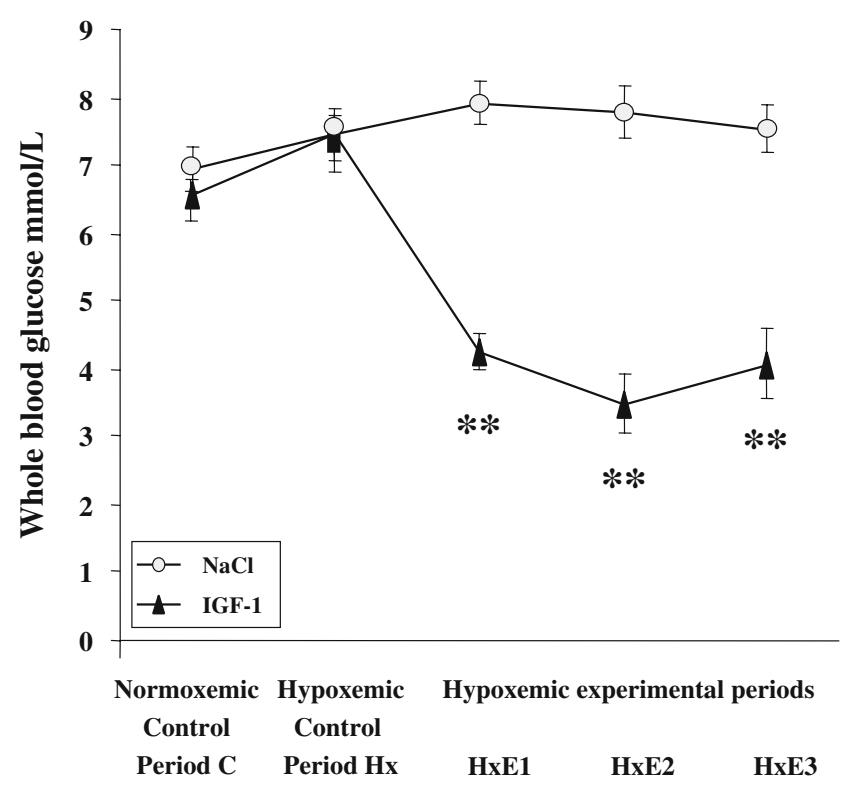

Fig. 3 Glucose whole-blood concentrations in two groups of newborn rabbits. Effect of i.v. administration of isotonic saline solution $(n=8)$ or IGF-1 $1 \mathrm{mg} / \mathrm{kg}(n=9)$. Values are means \pm SEMs. Asterisks indicate $P<0.01$ when compared with hypoxemic control period $\mathrm{Hx}$, using the non parametric Friedman test followed by the Wilcoxon matched-pairs signed-ranks test

decreased significantly but to a lesser extent and was relatively maintained. Although this result did not reach statistical significance, the FF tended to decrease in the IGF-1 group (Table 3), indicating vasodilation of renal afferent and efferent arterioles with a tendency to a preferential postglomerular localization. In the adult kidney, IGF-1 receptors (IGF-1Rs) are expressed and IGF-1 is released from glomeruli and glomerular mesangial cells in culture [16, 17, 33, 34]. IGF-1 binds to glomerular endothelial and epithelial cells, providing evidence for IGF-1 action in the renal glomerulus [15]. The rabbit fetal kidney expresses IGF-1 mRNA throughout late gestation and at birth [13]. Yet, during the first postnatal week, the levels of IGF-1R mRNA are low, progressively increasing until the end of the third week [18]. This suggests that the expression of IGF-1R is related to the postnatal acquisition of renal function. This was the time period when our experiments were performed. Despite the reported low expression of IGF-1R mRNA [18], our results demonstrated a functional expression pattern for IGF-1 and its receptors during the rabbits' first postnatal week of life.

These results are consistent with the observations reported for hypoxemia alone. They strengthen the notion of a vasomotor origin of the hypoxemia-induced insult on the immature kidney previously reported by our group [2$6]$ and suggest a role for IGF-1 deficiency in this complex phenomenon. In anesthetized adult rats given IGF-1, Baumann et al. reported an increase in GFR, renal plasma flow and diuresis by $35 \%, 100 \%$ and $300 \%$, respectively, whilst RVR decreased by $50 \%$. The FF was reduced, indicating predominant efferent vasodilation by IGF-1 [35]. Using the in vitro blood-perfused rat juxtamedullary nephron preparation, Tönshoff et al. demonstrated that the renal vascular effects of IGF-1 involve mainly the activation of two endogenous vasodilators, namely $\mathrm{NO}$ and vasodilatory prostaglandins (PGs). Addition of IGF-1 to the perfusate resulted in dose-dependent vasodilation of the preglomerular microvasculature that was totally inhibited by the NO synthase (NOS) inhibitor L-NAME [24]. It was also demonstrated that IGF-1 perfusion induced a direct increase in the concentration of $\mathrm{NO}$ in the renal microvasculature, regardless of the localization $[24,36]$. Acute IGF-1 stimulation increased $\mathrm{NO}$ production in rat glomeruli through a stimulatory effect on endothelial NOS (eNOS) message and protein expression [36]. This response was seen as early as $3 \mathrm{~h}$ after the beginning of incubation with IGF-1, which is a time-course consistent with our experiment. Our group previously demonstrated that L-NAME administration was accompanied by a worsening of the hypoxemia-induced renal vasoconstriction, suggesting that endogenous NO is functionally present in the immature kidney and that NOS activity is maintained during acute hypoxemia [6]. Moreover, endogenous NO maintains neonatal basal renal perfusion mainly through postglomerular renal vascular resistance [37].

We also previously demonstrated in the same model that the newborn's kidney is highly sensitive to cyclooxygenase 2 (COX2) inhibition and that PGs play a key role in the regulation of neonatal GFR [29], through a rapid increase of COX2 renal expression during the first two postnatal weeks $[38,39]$. Prostaglandin synthesis inhibition with indomethacin completely blocked the IGF-1-induced increase in GFR in vitro and in vivo [24, 40, 41]. Although direct stimulation of $\mathrm{PG}$ production by IGF-1 has not been described in renal cells, IGF-1 has been shown to stimulate PGE2 production indirectly in mesangial cells in culture by enhancing the interleukin-1 $\beta$ signaling pathway, which results in an increase in the activity of COX2 [42].

Therefore, we can assume that the stimulating effect of IGF-1 on both productions of NO and PGs was functional in our study and may be, at least in part, responsible for the vasodilation elicited by IGF-1.

Surprisingly, in contrast to these results, we reported that IGF-1 infusion in normoxemic newborn rabbits does not vasodilate, but rather vasoconstricts, the immature kidney [26]. This has already been reported in the fetal lamb, where IGF-1 infusion was associated with a marked increase in the activity and levels of renin in fetal plasma [43]. This might be the case in normoxemia, as the RAS is very active in the neonatal period $[26,44]$. However, we also previously demonstrated that hypoxemia leads to a 
state of intense RAS activation in this neonatal model [5, 44]. Additional vasoconstriction through IGF-1-induced secondary RAS activation may not have been possible here, and the vasodilatory NO- and PG-mediated activity of IGF-1 would have prevailed.

Whole-blood glucose levels were significantly decreased (Fig. 3). This well-described side effect of IGF-1 infusion may be explained by increased peripheral glucose use and inhibition of hepatic gluconeogenesis [45, 46]. It has been reported that glucagon increases GFR in adult dogs and humans but has no effect on the GFR of fetal sheep [47]. Contrariwise, L-glucose infusion in rats leads to a decrease in GFR, yet D-glucose has no effect [48]. Finally, serum IGF-1 concentrations not stimulating total body glucose disposal could affect renal hemodynamics, suggesting a direct role of IGF-1 receptor-mediated events independent of glucose metabolism [35]. In view of these conflicting results, we assumed that IGF-1-induced hypoglycemia in our newborn model may not have directly interfered with renal function. The metabolic effect of IGF-1 could then be regarded as evidence of IGF-1 efficiency and IGF-1 receptor activity.

In this study, we have demonstrated that exogenous IGF-1 administration to hypoxemic newborn rabbits can also prevent death from ARF (Fig. 2), despite low glucose blood levels and a decrease in blood pressure. These results are in contrast with findings by Fernandez et al., where IGF-1 administration increased the mortality rate of adult rats subjected to renal ischemia via bilateral renal pedicle occlusion for $75 \mathrm{~min}$ [49]. However, the ARF model was not identical, and the animals were adults, thus making it difficult for it to be compared with our study. A difference in the severity of ischemia-induced renal failure cannot be ruled out either.

IGF-1 has recently been shown to be a direct neuroprotective agent [50]. Apoptotic cell death induced by hypoxia-ischemia was correlated with a decrease of IGF-1 mRNA in the neonatal rat brain [51]. IGF-1 administration reduced hypoxia/ischemia-induced injury to the immature brain of 7-day old rats by approximately 40\% [52]. Likewise, IGF-1 protection against cell death and impaired myelination in a neonatal rat model of white matter damage was demonstrated [53]. Indirectly, IGF-1 also increased the hypoxia-inducible factor $1 \alpha(\mathrm{HIF}-1 \alpha)$ DNA binding activity and the survival of cultured primary neurons in 7-day old rats [54]. HIF-1 is an oxygen-regulated transcriptional complex that controls a large number of oxygen-regulated genes. An increase in HIF- $1 \alpha$ activity would result in metabolic, angiogenic and apoptotic adaptive responses, contributing to neuroprotection $[52,55]$. HIF- $1 \alpha$ accumulation and HIF-1 target gene activation were triggered by systemic administration of IGF-1 in the adult rat brain [55]. Because the level of hypoxia was profound in our model
(1\% oxygen), we can speculate that the neuroprotective action of IGF-1 played a role in the increase of survival rate seen in our model.

Finally, besides the positive influence of partial recovery of renal function, the beneficial effect of IGF-1 on survival may also result from a chronotropic effect of IGF-1, as heart rate statistically increased during IGF-1 infusion. Direct inotropic effects of IGF-1 have been described in neonatal rat cardiomyocytes in vitro, demonstrating the sensitivity of the neonatal heart to IGF-1 [56]. In dogs followed by telemetry, heart rate continuously increased for approximately $90 \mathrm{~min}$ after treatment, whilst both systolic and diastolic blood pressures decreased [57].

\section{Conclusion}

In conclusion, our study provided evidence that short-term changes of renal function parameters can be achieved by systemic infusion of IGF-1. Although hypoxemia-induced ARF could not be totally prevented, IGF-1 elicited vasodilation, thereby precluding a further hypoxemia-induced decline in renal function. These results confirm that the renal microvasculature in the neonatal period is sensitive to exogenous IGF-1, even in pathogenic circumstances. Combined with the high survival rate seen with IGF-1, these results could be of clinical importance, as neonatal mortality and morbidity rates due to ARF remain very high [2].

Acknowledgments We wish to thank Prof. Jean-Pierre Guignard for allowing us the unique opportunity to work with him, as well as the freedom to work independently for the present project. We wish to thank the Swiss National Science Foundation (SNSF) for supporting the Pediatric Nephrology Unit of the Lausanne University Medical Center (CHUV) throughout the years. Dr A. Prévot and this study were supported by SNSF grant no. 3200-064041.00.

\section{References}

1. Flynn JT (1998) Causes, management approaches, and outcome of acute renal failure in children. Curr Opin Pediatr 10:184-189

2. Toth-Heyn P, Drukker A, Guignard JP (2000) The stressed neonatal kidney: from pathophysiology to clinical management of neonatal vasomotor nephropathy. Pediatr Nephrol 14:227-239

3. Prévot A, Mosig D, Rijtema M, Guignard JP (2003) Renal effects of adenosine A1-receptor blockade with 8-cyclopentyl-1,3-dipropylxanthine in hypoxemic newborn rabbits. Pediatr Res 54:400-405

4. Prévot A, Huet F, Semama DS, Gouyon JB, Guignard JP (2002) Complementary effects of adenosine and angiotensin II in hypoxemiainduced renal dysfunction in the rabbit. Life Sci 71:779-787

5. Huet F, Semama DS, Gouyon J-B, Guignard JP (1999) Protective effect of perindoprilat in the hypoxemia-induced renal dysfunction in the neonatal rabbit. Pediatr Res 45:138-142

6. Ballèvre L, Thonney M, Guignard JP (1996) Role of nitric oxide in the hypoxemia-induced renal dysfunction of the newborn rabbit. Pediatr Res 39:725-730 
7. Feld S, Hirschberg R (1996) Growth hormone, the insulin-like growth factor system, and the kidney. Endocr Rev 17:423-480

8. Hirschberg R, Kopple JD (1989) Evidence that insulin-like growth factor I increases renal plasma flow and glomerular filtration rate in fasted rats. J Clin Invest 83:326-330

9. Rogers SA, Powell-Braxton L, Hammerman MR (1999) Insulinlike growth factor I regulates renal development in rodents. Dev Genet 24:293-298

10. Randhawa R, Cohen P (2005) The role of the insulin-like growth factor system in prenatal growth. Mol Genet Metab 86:84-90

11. Kim WK, Ryu YH, Seo DS, Lee CY, Ko Y (2005) Effects of oral administration of insulin-like growth factor-I on circulating concentration of insulin-like growth factor-I and growth of internal organs in weanling mice. Biol Neonate 89:199-204

12. Mahesh S, Kaskel F (2008) Growth hormone axis in chronic kidney disease. Pediatr Nephrol 23:41-48

13. Thakur A, Sase M, Lee JJ, Thakur V, Buchmiller TL (2000) Ontogeny of insulin-like growth factor 1 in a rabbit model of growth retardation. J Surg Res 91:135-140

14. Fowden AL (2003) The insulin-like growth factors and fetoplacental growth. Placenta 24:803-812

15. Conti FG, Elliot SJ, Striker LJ, Striker GE (1989) Binding of insulin-like growth factor-I by glomerular endothelial and epithelial cells: further evidence for IGF-I action in the renal glomerulus. Biochem Biophys Res Commun 163:952-958

16. Haskell JF, Pillion DJ, Meezan E (1988) Specific, high affinity receptors for insulin-like growth factor II in the rat kidney glomerulus. Endocrinology 123:774-780

17. Arnqvist HJ, Ballermann BJ, King GL (1988) Receptors for and effects of insulin and IGF-I in rat glomerular mesangial cells. Am J Physiol 254:C411-C416

18. Ojeda JL, Berciano MT, Polanco JI, Lafarga M, Rodriguez-Rey JC (1997) Insulin-like growth factor I receptor gene expression during postnatal development of rabbit kidney. Anat Rec 249:187-195

19. Satar M, Ozcan K, Yapicioglu H, Narli N (2004) Serum insulinlike growth factor 1 and growth hormone levels of hypoxicischemic newborns. Biol Neonate 85:15-20

20. Tsao T, Wang J, Fervenza FC, Vu TH, Jin IH, Hoffman AR, Rabkin R (1995) Renal growth hormone-insulin-like growth factor-I system in acute renal failure. Kidney Int 47:1658-1668

21. Bennet L, Oliver MH, Gunn AJ, Hennies M, Breier BH (2001) Differential changes in insulin-like growth factors and their binding proteins following asphyxia in the preterm fetal sheep. $\mathrm{J}$ Physiol 531:835-841

22. Ding H, Kopple JD, Cohen A, Hirschberg R (1993) Recombinant human insulin-like growth factor-I accelerates recovery and reduces catabolism in rats with ischemic acute renal failure. $\mathrm{J}$ Clin Invest 91:2281-2287

23. Bohé J, Ding H, Qing DP, Yoon K, Hirschberg R, Wolfgang GHI, Kopple JD (1998) IGF-I binding proteins, IGF-I binding protein mRNA and IGF-I receptor mRNA in rats with acute renal failure given IGF-I. Kidney Int 54:1070-1082

24. Tönshoff B, Kaskel FJ, Moore LC (1998) Effects of insulin-like growth factor I on the renal juxtamedullary microvasculature. Am J Physiol 274:F120-F128

25. Gouyon JB, Valloton M, Guignard JP (1987) The newborn rabbit: a model for studying hypoxemia-induced renal changes. Biol Neonate 52:115-120

26. Prévot A, Mosig D, Guignard JP (2004) Effect of IGF1 administration on the newborn kidney. Pediatr Nephrol 19:C251

27. Wright HK, Gann DS (1966) An automatic anthrone method for the determination of inulin in plasma and urine. J Lab Clin Med 67:689-693

28. Bratton AC, Marshall EK (1939) A new coupling component for sulfanilamide determination. J Biol Chem 128:537-550
29. Prévot A, Mosig D, Martini S, Guignard JP (2004) Nimesulide, a cyclooxygenase- 2 preferential inhibitor, impairs renal function in the newborn rabbit. Pediatr Res 55:254-260

30. Huet F, Gouyon JB, Guignard JP (1997) Prevention of hypoxemiainduced renal dysfunction by perindoprilat in the rabbit. Life Sci 61:2157-2165

31. Prévot A, Mosig D, Guignard JP (2002) The effects of losartan on renal function in the newborn rabbit. Pediatr Res 51:728-732

32. Iwamoto HS, Murray MA, Chernausek SD (1992) Effects of acute hypoxemia on insulin-like growth factors and their binding proteins in fetal sheep. Am J Physiol 263:E1151-E1156

33. Conti FG, Striker LJ, Elliot SJ, Andreani D, Striker GE (1988) Synthesis and release of insulin-like growth factor I by mesangial cells in culture. Am J Physiol 255:F1214-F1219

34. Pillion DJ, Haskell JF, Meezan E (1988) Distinct receptors for insulin-like growth factor I in rat renal glomeruli and tubules. Am J Physiol 255:E504-E512

35. Baumann U, Eisenhauer T, Hartmann H (1992) Increase of glomerular filtration rate and renal plasma flow by insulin-like growth factor-I during euglycaemic clamping in anaesthetized rats. Eur J Clin Invest 22:204-209

36. Wang Y, Nagase S, Koyama A (2004) Stimulatory effect of IGF-I and VEGF on eNOS message, protein expression, eNOS phosphorylation and nitric oxide production in rat glomeruli, and the involvement of PI3-K signaling pathway. Nitric Oxide 10:25-35

37. Ballèvre L, Thonney M, Guignard JP (1996) Nitric oxide modulates glomerular filtration and renal blood flow of the newborn rabbit. Biol Neonate 69:389-398

38. Schumacher K, Castrop H, Strehl R, de Vries U, Minuth WW (2002) Cyclooxygenases in the collecting duct of neonatal rabbit kidney. Cell Physiol Biochem 12:63-74

39. Zhang MZ, Wang JL, Cheng HF, Harris RC, McKanna JA (1997) Cyclooxygenase-2 in rat nephron development. Am J Physiol 273: F994-F1002

40. Hirschberg R, Kopple JD, Blantz RC, Tucker BJ (1991) Effects of recombinant human insulin-like growth factor I on glomerular dynamics in the rat. J Clin Invest 87:1200-1206

41. Tönshoff B, Nowack R, Kurilenko S, Blum WF, Seyberth HW, Mehls O, Ritz E (1993) Growth hormone-induced glomerular hyperfiltration is dependent on vasodilating prostanoids. Am J Kidney Dis 21:145-151

42. Guan Z, Buckman SY, Baier LD, Morrison AR (1998) IGF-I and insulin amplify IL-1 beta-induced nitric oxide and prostaglandin biosynthesis. Am J Physiol 274:F673-F679

43. Marsh AC, Gibson KJ, Wu J, Owens PC, Owens JA, Lumbers ER (2001) Insulin-like growth factor I alters renal function and stimulates renin secretion in late gestation fetal sheep. J Physiol 530:253-262

44. Guignard JP, Gouyon JB, John EG (1991) Vasoactive factors in the immature kidney. Pediatr Nephrol 5:443-446

45. Kovacs GT, Worgall S, Schwalbach P, Steichele T, Mehls O, Rosivall L (1999) Hypoglycemic effects of insulin-like growth factor-1 in experimental uremia: can concomitant growth hormone administration prevent this effect? Horm Res 51:193-200

46. Di Cola G, Cool MH, Accili D (1997) Hypoglycemic effect of insulin-like growth factor-1 in mice lacking insulin receptors. J Clin Invest 99:2538-2544

47. Moore RS, Lumbers ER (1992) Renal and metabolic effects of glucagon in the fetus. J Dev Physiol 17:47-49

48. Boland PS, Garland HO (1993) Effects of D-glucose, L-glucose and D-mannitol on renal calcium handling and general renal function in the rat. Exp Physiol 78:165-174

49. Fernandez M, Medina A, Santos F, Carbajo E, Rodriguez J, Alvarez J, Cobo A (2001) Exacerbated inflammatory response induced by insulin-like growth factor I treatment in rats with ischemic acute renal failure. J Am Soc Nephrol 12:1900-1907 
50. Smith PF (2003) Neuroprotection against hypoxia-ischemia by insulin-like growth factor-I (IGF-I). IDrugs 6:1173-1177

51. Clawson TF, Vannucci SJ, Wang GM, Seaman LB, Yang XL, Lee WH (1999) Hypoxia-ischemia-induced apoptotic cell death correlates with IGF-I mRNA decrease in neonatal rat brain. Biol Signals Recept 8:281-293

52. Brywe KG, Mallard C, Gustavsson M, Hedtjarn M, Leverin AL, Wang X, Blomgren K, Isgaard J, Hagberg H (2005) IGF-I neuroprotection in the immature brain after hypoxia-ischemia, involvement of Akt and GSK3beta? Eur J Neurosci 21:1489-1502

53. Lin S, Fan LW, Pang Y, Rhodes PG, Mitchell HJ, Cai Z (2005) IGF-1 protects oligodendrocyte progenitor cells and improves neurological functions following cerebral hypoxia-ischemia in the neonatal rat. Brain Res 1063:15-26
54. Wang X, Deng J, Boyle DW, Zhong J, Lee WH (2004) Potential role of IGF-I in hypoxia tolerance using a rat hypoxic-ischemic model: activation of hypoxia-inducible factor 1alpha. Pediatr Res 55:385-394

55. Chavez JC, LaManna JC (2002) Activation of hypoxia-inducible factor-1 in the rat cerebral cortex after transient global ischemia: potential role of insulin-like growth factor-1. J Neurosci 22:8922-8931

56. Vetter U, Kupferschmid C, Lang D, Pentz S (1988) Insulin-like growth factors and insulin increase the contractility of neonatal rat cardiocytes in vitro. Basic Res Cardiol 83:647-654

57. Ilbäck NG, Gunnarsson K, Stalhandske T (2002) Effects of rhIGF-I and insulin-induced hypoglycaemia on cardiovascular parameters recorded with telemetry in the conscious dog. Pharmacol Toxicol 90:73-81 